\title{
PREVALENCE AND RISK FACTORS ASSOCIATED WITH URINARY INCONTINENCE IN CLIMATE WOMEN
}

\section{Fernanda Paluszkiewicz Dullius*1, Ronilson Ferreira Freitas ${ }^{2}$, João Pedro Brant Rocha ${ }^{3}$, Fernanda Piana Santos Lima Oliveira ${ }^{4}$, Maria Clara Brant Rocha ${ }^{5}$, Maria Suzana Marques ${ }^{6}$, João Gustavo Brant Rocha7, Fabiana Aparecida Maia Borborema ${ }^{8}$, Dorothéa Schmidt França ${ }^{9}$, Carolina Ananias Meira Trovão ${ }^{10}$, Jamile Pereira Dias dos Anjos ${ }^{11}$, Viviane Maia Santos ${ }^{12}$, Daniela Araújo Veloso Popoff ${ }^{13}$ and Josiane Santos Brant Rocha ${ }^{14}$}

\begin{abstract}
${ }^{1}$ Master in Primary Health Care, State University of Montes Claros, Montes Claros, Minas Gerais, Brazil. ${ }^{2} \mathrm{PhD}$ Health Sciences, State University of Montes Claros, Montes Claros, Minas Gerais, Brazil. ${ }^{3}$ Medicine, Federal University of Minas Gerais, Belo Horizonte, Minas Gerais, Brazil. ${ }^{4} \mathrm{PhD}$ in Public Health at Federal University of Minas Gerais. Professor at the UniFipMoc University Center, Montes Claros Minas Gerais, Brazil. ${ }^{5}$ Medicine, Faculty of Medical Sciences of Minas Gerais, Belo Horizonte, Minas Gerais, Brazil. ${ }^{6}$ Master in Primary Health Care, StateUniversityof Montes Claros, Montes Claros, Minas Gerais, Brazil. 7Medicine, Faculty of Medical Sciences of Minas Gerais, Belo Horizonte, Minas Gerais, Brazil. ${ }^{8}$ Master in Primary Health Care, State University of Montes Claros, Montes Claros, Minas Gerais, Brazil. ${ }^{9} \mathrm{PhD}$ in Biological Sciences - Pharmacology and Physiology from the Federal University of Minas Gerais. Professor at the UniFipMoc University Center, Montes Claros - Minas Gerais, Brazil. 10Master in Primary Health Care, State University of Montes Claros, Montes Claros, Minas Gerais, Brazil. ${ }^{11}$ Master in Primary Health Care, StateUniversityof Montes Claros, Montes Claros, Minas Gerais,

Brazil. 12Master in Primary Health Care, State University of Montes Claros, Montes Claros, Minas Gerais, Brazil; ${ }^{13} \mathrm{PhD}$ in Dental Clinic from the Federal University of Minas Gerais. Professor at the State University of Montes Claros and at the Center, Montes Claros - Minas Gerais, Brazil; ${ }^{14} \mathrm{PhD}$ in Sports Sciences at Trás-os-Montes and Alto Douro University, Portugal. Professor at the State University of Montes Claros and at the UniFipMoc University Center, Montes Claros - Minas Gerais, Brazil
\end{abstract}

\section{ARTICLE INFO}

Article History:

Received $11^{\text {th }}$ February, 2021

Received in revised form

$04^{\text {th }}$ March, 2021

Accepted $16^{\text {th }}$ April, 2021

Published online $30^{\text {th }}$ May, 2021

\section{Key Words:}

Prevalence;

Urinaryincontinence;

Climacteric.

*Corresponding autho:

Fernanda Paluszkiewicz Dullius,

\begin{abstract}
To investigate the prevalence and factors associated with urinary incontinence (IU) in climacteric women attending the Family Health Strategies. Cross-sectional study with 874 climacteric women, selected by probabilistic sampling. The variables were investigated by a structured/pretested questionnaire. Bivariate analysis was performed using the chi-square test for variable selection for the multiple model adopting $\mathrm{p} \leq 0.25$. In multivariate analysis, binary logistic regression was used to obtain adjusted odds ratios. After the analysis, the final model was constructed, adopting a significance level of $\mathrm{p} \leq 0.05$. The prevalence of urinary tract infection was $22.5 \%$. After adjustments, the odds of urinary incontinence referred to these variables: single, sedentary/irregularly active women, smokers, overweight, obese women with severe climacteric symptoms, having episiotomy and presenting ovarian cysts. It was concluded that the presence of modifiable factors were associated with urinary incontinence.
\end{abstract}

Copyright (C) 2021, Fernanda Paluszkiewicz Dullius et al. This is an open access article distributed under the Creative Commons Attribution License, which permits unrestricted use, distribution, and reproduction in any medium, provided the original work is properly cited.

Citation: Fernanda Paluszkiewicz, Dullius, Ronilson Ferreira Freitas, João Pedro Brant Rocha, Fernanda Piana Santos Lima Oliveira, Maria Clara Brant Rocha, Maria Suzana Marques, João Gustavo Brant Rocha, et al. 2021. "Prevalence and risk factors associated with urinary incontinence in climate women", International Journal of Development Research, 11, (05), 47146-47151.

\section{INTRODUCTION}

In recent years there has been an increase in life expectancy of the Brazilian population with consequent aging of the population ${ }^{[1,2]}$. Census data from the Brazilian Institute of Geography and Statistics ${ }^{[1]}$ showed that the Brazilian population is more female, $51.3 \%$, and also older. This transition has aroused greater concern and interest in health and quality oflife of women in the climacteric period.
Faced with this new reality, the need arises for new guidelines and behaviors concerning perimenopause and in the female aging process, and also about the pathologies which may relate to this population ${ }^{[3]}$. The climacteric is known as transition from reproductive status to the non-reproductive status. It is marked by physiological hormonal changes, and which have a higher prevalence of diseases and disorders that can result in persistent symptoms or an onset of new symptoms of the urinary tract, among them urinary incontinence 
$(\mathrm{UI})^{[3]}$. This morbidity appears as a major health problem in public health in women in older age groups ${ }^{[4,5]}$ with an impact on morbidity ${ }^{[3]}$, with an increase in people looking for health services and a decrease in quality of life ${ }^{[6]}$.According to the International Continence Society (ICS), the urinary incontinence is a condition defined as any involuntary loss of urine ${ }^{[7]}$, characterized by the dysfunction of the lower urinary tract and changes in the physiological urination process or the support of the organs responsible for it.

The urinary incontinence is a multifactorial disease and some factors such as gynecological history, non-transmittable chronic diseases, obesity, age and hormonal changes are highlighted in its development ${ }^{[5,8-10]}$. Discomfort and social isolation, affect the basic activities of daily life,and the perception of their own health, had a significant impact on health quality ${ }^{[11]}$. Considering that the urinary incontinence includes a major geriatric syndrome group ${ }^{[12]}$ and perimenopause stands out as a period with increased risk for the onset of diseases in women ${ }^{[3]}$, it becomes relevant to do studies on what provokes a greater reflection on this theme. Thus, the aim of this study was to investigate the prevalence and factors associated with urinary incontinence in climacteric women assisted in the ESFs.

\section{METHODS}

We developed an analytical epidemiological study, based on the population. The whole studywas made up of 874 women aged 40-65 years of age who were from the units of Family Health Strategys, located in the urban area of the municipality of Montes Claros/MG, Brazil. The size of the sample was obtained by a selection technique by conglomerates in 73 units of Family Health Strategysin Montes Claros, who were registered in the year of 2014 and following this, the probability sampling was conducted among postmenopausal women in its various phases (pre, peri and post-menopausal), followed up in the coverage areas of Family Health Strategy in the period from August 2014 to August 2015. In order to incorporate the structure of the complex sample design on statistical analysis of the data, each respondent was associated with a weight $\mathrm{w}$, corresponding to the inverse of its probability of inclusion in the sample (f). Individual pregnant women, mothers and bedridden people were adopted as a criterion for non-inclusion in this study.

The study included only those who signed the freeand informed Consent. Socio-demographic data such as age (40-45, 46-51, 52-65 years), marital status (with or without a partner), education (elementary I and II, High School and higher education), work (yes/no) and color/race (black, white or another colors); lifestyle: physical activity (active, very active and sedentary) and smoking (yes/no); clinical and obstetric factors, symptoms and stages of menopause (mild, moderate or severe, pre, peri and post menopause, respectively, type of menopause (natural or induced), menarche (early - up to 11 years of age, normal - 12 to 14 years of age and late after 15 years of age), age at first birth(before or after 18 years of age), episiotomy (yes/no), ovarian cyst (yes/no), perineoplasty(yes/no) risk for cardiovascular disease (low, intermediate, high), diabetes (yes/no), depression (mild, moderate or severe) and metabolic syndrome (yes/no) were collected using a structured questionnaire applied to menopausal women and the metabolic syndrome confirmed by laboratory analysis.

Anthropometric measurements (waist circumference (WC), weight and height) and the classification of body mass index (BMI). Values $\geq 88 \mathrm{~cm}$ in WC were classified as altered, as for the BMI, research in eutrophics were adopted(18.5-24.9), overweight (25.0-29.9) and obesity (30.0 - above), following the recommendations of the World Health Organization (WHO) ${ }^{[13,14]}$. After the random draw of women, the same were invited by the community health workers, to attend the Family Health Strategy to carry out evaluations. The collection was carried out by a previously trained and calibrated staff and which happened in private. First blood samples were collected for laboratory analysis. After the anthropometric and blood pressure measurements were done and then the applied questionnaires. Self-reported urinary incontinence prevalence was evaluated and the quantification of loss through the instrument validated for the Brazilian reality, the International Consultation on Incontinence Questionnaire - Short Form (ICIQ-SF) ${ }^{[15]}$.The ICIQ-SF is a simple, self-administered questionnaire composed of four questions that evaluatethe frequency and severity of urinary incontinence. Women who reported involuntary urine loss were considered incontinent. Data was tabulated in the statistical program Statistical Package for Social Sciences version 21.0 (SPSS) and a descriptive statistic analysis was made(absolute frequency and relative).

In order to analyze the associations between the dependent variable (urinary incontinence) and the independent variables (sociodemographic, lifestyle, anthropometric measurements, clinical and obstetrical factors). The bivariate analysis was performed by using the chi-square test for the selection of variables for the multiple model being adopted $p \leq 0,25$. At the stage of the multivariate analysis, binary logistic regression was used to obtain the ratios of adjusted odds. After analysis, the final model was built, adopting a significance level of $\mathrm{p} \leq 0.05$. The study was approved by the Research Ethics Committee of the Integrated Colleges Pitágoras Montes Claros with opinion No. 817,666, and which carefully followed all the ethical precepts of Resolution 466/2012.

\section{RESULTS}

Most women with urinary incontinence, participants of the research were aged between 52-65 years of age $(45.4 \%)$ had completed elementary education level I $(41.6 \%)$. In relation to life habits, sedentary women or irregularly active women predominated $[87.3 \%$ ), non-smokers $(89.8 \%)$. In total $(36 \%)$ were obese and $(63.8 \%)$ had changed measures abdominal circumference. As for the symptoms and stages of menopause, mild symptoms were shown $(62.3 \%)$ found themselves in postmenopausal (4.3\%). Most of the women had done episiotomy $(57.8 \%)$ showed no ovarian cyst $(84.1 \%)$ and hadn't doneperineoplasty $(86.3 \%$ ) (Table 1$)$. In the sample, there was a prevalence of urinary incontinence of $22.5 \%(n=195)$ with $95 \%$ $(19.2 \%-26.3 \%)$. As for the loss of urine, the majority $(77.5 \%)$ reported that they had never lost urine.

The referred factors associated with urinary incontinenceare presented in Table 3. In the crude analysis, an association was found between the urinary incontinence with the sociodemographic variables, life habits, anthropometrics, obstetric and clinical factors. Women from 46-51 years of age and 52-65 years of age $(\mathrm{p}=0.077)$, without a partner $(\mathrm{p}=0.083)$, white skin color $(\mathrm{p}=0.069)$, with schooling ranging from fundamental I and $\mathrm{II}(\mathrm{p}=0.047)$, which do not work $(p=0.224)$, sedentary/irregularly active $(p=0.128)$, smoking $(p=0.049)$, overweight and with obesity $(p=0.013)$, which had abdominal circumference changed $(\mathrm{p}=0.122)$, symptomatologyof the climacteric moderate intense $(\mathrm{p}=0.000)$ in peri- and postmenopausal women $(\mathrm{p}=0.183)$, with induced menopause $(\mathrm{p}=0.202)$, normal and late menarche $(\mathrm{p}=0.159)$, with the age of first birth above 18 years of $\operatorname{age}(p=0.013)$, who had undergone episiotomy $(p=0.028)$, that presented ovarian cyst $(\mathrm{p}=0.012)$ with perineoplasty $(\mathrm{p}=0.057)$, with diabetes $(p=0.136)$, which showed medium risk and high risk for cardiovascular diseases $(\mathrm{p}=0.078)$, which had moderate or severe depression $(\mathrm{p}=0.003)$ and with a metabolic syndrome $(\mathrm{p}=0.157)$ were more likely to have urinary incontinence.

After an adjusted analyses, the chances of having UI referred to the following variables: unmarried women (OR 1.38 95\% CI 0.97 to 1.99), sedentary/irregularly active women(OR 2.14 95\% CI 1.17 3.93), smokers (OR $1.7995 \%$ CI 1.05 to 3.03), overweight women(OR $1.3095 \%$ CI 0.80 to 2.10 ), obese women(OR $1.92 \mathrm{CI}$ $95 \% 1.21$ to 3.09 ), women with intense climacteric symptoms (OR 2.52 CI 1.48 to 4.29 ), or that had performed episiotomy (OR 1.47 95\% CI 1.03 to 2.12 ) and having ovarian cyst (OR $1.71 ; 95 \%$ CI 1.11 to 2.64) (Table 3). 
Table 1. Characterization of the Sample according to the demographic social factors, life habits, anthropometric measurements, clinical and obstetrical factors of climacteric women, Montes Claros-MG, 2014

\begin{tabular}{|c|c|c|c|}
\hline \multicolumn{2}{|c|}{ Variables } & \multirow[t]{2}{*}{$\mathrm{n}$} & \multirow[t]{2}{*}{$\% *$} \\
\hline Socio-demographicfactors & & & \\
\hline \multirow{3}{*}{ Age } & 40 to 45 yearsof age & 236 & 27.9 \\
\hline & 46 to 51 yearsof age & 241 & 26.8 \\
\hline & 52 to 65 yearsof age & 397 & 45.4 \\
\hline \multirow[t]{2}{*}{ Spousalsituation } & With a companion & 559 & 63.0 \\
\hline & Without a companion & 313 & 37.0 \\
\hline \multirow[t]{4}{*}{ Color } & Black & 112 & 12.6 \\
\hline & White & 154 & 17.2 \\
\hline & Othercolors & 602 & 71.1 \\
\hline & High School/College & 281 & 31.8 \\
\hline \multirow[t]{2}{*}{ Education } & Fundamental II & 231 & 26.6 \\
\hline & Fundamental I & 358 & 41.6 \\
\hline \multirow[t]{2}{*}{ work } & Yes & 347 & 40.4 \\
\hline & No & 520 & 59.6 \\
\hline \multicolumn{4}{|l|}{ Life Habits } \\
\hline \multirow[t]{2}{*}{ Physicalactivity } & Active/Very Active & 114 & 12.7 \\
\hline & Sedentary/Active Irregularly & 760 & 87.3 \\
\hline \multirow[t]{2}{*}{ Smoking } & No & 739 & 89.8 \\
\hline & Yes & 80 & 10.2 \\
\hline \multicolumn{4}{|c|}{ Anthropometricmeasurements } \\
\hline \multirow[t]{3}{*}{ BMI } & Properweight & 228 & 25.9 \\
\hline & Overweight & 333 & 38.0 \\
\hline & Obesity & 306 & 36.0 \\
\hline \multirow[t]{2}{*}{ WC } & Normal & 331 & 36.2 \\
\hline & Changed & 538 & 63.8 \\
\hline \multicolumn{4}{|l|}{ ClinicalandObstetricfactors } \\
\hline & Light & 541 & 62.3 \\
\hline \multirow[t]{3}{*}{ SymptomsofMenopause } & Moderate & 246 & 27.9 \\
\hline & Intense & 86 & 9.8 \\
\hline & Premenopausal & 214 & 24.4 \\
\hline \multirow[t]{2}{*}{ Climactericphases } & perimenopause & 185 & 21.3 \\
\hline & Postmenopausal & 473 & 54.3 \\
\hline \multirow[t]{3}{*}{ TypeofMenopause } & Natural & 338 & 82.9 \\
\hline & induced & 66 & 17.1 \\
\hline & Early - up to 11 years old & 101 & 11.8 \\
\hline \multirow[t]{2}{*}{ Menarche } & Normal -12 to 14 yearsold & 513 & 60.6 \\
\hline & Late -15 yearsorolder & 260 & 27.6 \\
\hline \multirow[t]{2}{*}{ Age offirstbirth } & Birth until 18 years of age & 218 & 27.3 \\
\hline & Birth over 18 years of age & 605 & 72.7 \\
\hline Episiotomy & No & 370 & 43.2 \\
\hline & Yes & 500 & 57.8 \\
\hline Cyst in theovarian & No & 719 & 84.1 \\
\hline & Yes & 146 & 15.9 \\
\hline Perineoplasty & No & 748 & 86.3 \\
\hline & Yes & 119 & 13.7 \\
\hline Diabetes & No & 682 & 78.3 \\
\hline & Yes & 183 & 21.7 \\
\hline & LowRisk & 406 & 44.9 \\
\hline Cardiovascular disease & Intermediaterisk & 423 & 47.4 \\
\hline & High Risk & 66 & 7.8 \\
\hline Depression & minimalormilddepression & 748 & 86.0 \\
\hline & moderateorseveredepression & 121 & 14.0 \\
\hline SM & Absence & 406 & 44.4 \\
\hline & Presence & 487 & 55.6 \\
\hline
\end{tabular}

BMI: body mass index; WC: waist circumference; $\% *$ Corrected by the effect of the design. [deff).

Table 2. Sample characterization according to variables related to urinary incontinence in menopausal women, Montes Claros-MG, 2014

\begin{tabular}{|c|c|c|c|}
\hline \multicolumn{2}{|c|}{ Urinaryincontinence } & \multirow{2}{*}{$\frac{n}{676}$} & \multirow{2}{*}{$\frac{\% *}{77,5}$} \\
\hline Urinaryincontinence* & Absence of Urinary Incontinence & & \\
\hline & PresenceofUrinaryIncontinence & 195 & 22,5 \\
\hline \multirow[t]{6}{*}{ Frequencyof Urine leakage* } & Never & 676 & 77,5 \\
\hline & Once a week or less & 072 & 8,4 \\
\hline & Three or four times a week & 033 & 3,7 \\
\hline & Once a day & 031 & 3,5 \\
\hline & Many times throughout the day & 046 & 5,3 \\
\hline & Allthe time & 013 & 1,6 \\
\hline
\end{tabular}


Table 3.Prevalence of urinary incontinence (UI), odds ratio (OR) crude and adjusted according to sociodemographic factors, lifestyle habits, anthropometric measurements clinical and obstetric factors of perimenopausal women, Montes Claros-MG, 2014

\begin{tabular}{|c|c|c|c|c|c|c|}
\hline \multirow[t]{2}{*}{ Variables } & & Presence UI & $\mathrm{OR}\left[\mathrm{IC}_{95 \%}\right)$ & \multirow[t]{2}{*}{$\mathrm{p}$} & $\mathrm{OR}\left[\mathrm{IC}_{95 \%}\right)$ & \multirow[t]{2}{*}{$\mathrm{p}$} \\
\hline & & $\%$ & Gross & & adjusted & \\
\hline \multicolumn{7}{|l|}{ Sociodemographicfactors } \\
\hline \multirow[t]{3}{*}{ Age } & 40 to 45 yearsof age & 18.6 & 1 & 0.077 & ------ & ------ \\
\hline & 46 to 51 years of age & 20.4 & $1.12[0.71-1.76)$ & & ------ & \\
\hline & 52 to 65 years of age & 25.8 & $1.52[1.02-2.26)$ & & ------ & \\
\hline \multirow[t]{2}{*}{ Spousalsituation } & With a companion & 20.6 & 1 & & & \\
\hline & Without a companion & 25.7 & $1.33[0.96-1.85)$ & 0.083 & $1.38[0.97-1.99)$ & 0.070 \\
\hline \multirow[t]{3}{*}{ Color } & Black & 20.7 & 1 & 0.069 & ----- & ------ \\
\hline & White & 29.2 & $1.58[0.89-2.81)$ & & ----- & \\
\hline & Othercolors & 20.7 & $0.99[0.60-1.64)$ & & ----- & \\
\hline \multirow[t]{3}{*}{ Education } & Education [High school+ College) & 19.3 & 1 & 0.047 & ----- & ------ \\
\hline & Fundamental II & 19.9 & $1.04[0.67-1.61)$ & & ------ & \\
\hline & Fundamental I & 26.7 & $1.52[1.04-2.22)$ & & ----- & \\
\hline \multirow[t]{2}{*}{ Work } & Work & 20.0 & 1 & & ----- & \\
\hline & Don'twork & 23.5 & $1.23[0.88-1.71)$ & 0.224 & ------ & ------ \\
\hline \multicolumn{7}{|l|}{ lifestyle } \\
\hline \multirow{2}{*}{ Physicalactivity } & Active / Veryactive & 16.8 & 1 & & 1 & \\
\hline & Sedentary / activeIrregularly & 23.2 & $1.50[0.89-2.52)$ & 0.128 & $2.14[1,17-3.93)$ & 0.014 \\
\hline \multirow[t]{2}{*}{ Smoking } & No & 21.5 & 1 & & & \\
\hline & Yes & 31.2 & $1.66[1.00-2.75)$ & 0.049 & $1.79[1.05-3.03)$ & 0.031 \\
\hline \multicolumn{7}{|c|}{ Anthropometricmeasurements } \\
\hline \multirow[t]{3}{*}{ BMI } & properweight & 17.5 & 1 & & 1 & \\
\hline & overweight & 20.8 & $1.24[0.80-1.91)$ & & $1.30[0.80-2.10)$ & 0.280 \\
\hline & Obesity & 27.8 & $1.81[1.18-2.76)$ & 0.013 & $1.92[1.21-3.09)$ & 0.006 \\
\hline \multirow[t]{2}{*}{ WC } & Normal & 19.7 & 1 & & ------ & ------ \\
\hline & changed & 24.2 & $1.30[0.93-1.82)$ & 0.122 & ------ & \\
\hline \multicolumn{7}{|c|}{ ClinicalandObstetricfactors } \\
\hline \multirow[t]{3}{*}{ SymptomsofMenopause } & Light & 17.6 & 1 & & 1 & \\
\hline & Moderate & 28.6 & $1.87[1.31-2.67)$ & 0,000 & $1.87[1.27-2.76)$ & 0.002 \\
\hline & Intense & 35.3 & $2,55[1,55-4,20)$ & & $2.52[1.48-4.29)$ & 0.001 \\
\hline ClimactericPhase & Premenopausal & 17.8 & 1 & & ----- & \\
\hline & perimenopause & 23.8 & $1.44[0.88-2.34)$ & 0.183 & ------ & ------ \\
\hline & Postmenopausal & 23.9 & $1.45[0.96-2.18)$ & & ------ & \\
\hline TypeMenopause & Natural & 22.9 & 1 & & ------ & \\
\hline & induced & 30.3 & $1.46[0.81-2.62)$ & 0.202 & ------ & ------ \\
\hline & Early - upto 11 years & 23.8 & 1 & & ------ & \\
\hline Menarche & Normal - 12 to 14 years & 24.2 & $0.98[0.59-1.61)$ & 0.159 & ------ & ------ \\
\hline & Late - 15 yearsor over & 18.2 & $0.70[0.48-1.01)$ & & ------ & \\
\hline Age ofFirstBirth & Birth until 18 years of age & 28.4 & 1 & 0.013 & ------ & \\
\hline & Birth over 18 years of age & 20.3 & $0.64[0.45-091)$ & & ----- & ------ \\
\hline episiotomy & No & 18.8 & 1 & 0.028 & 1 & \\
\hline & Yes & 25.1 & $1.45[1.04-.02)$ & & $1.47[1.03-2.12)$ & 0.036 \\
\hline Cyst in the ovarian & No & 20.7 & 1 & 0.012 & 1 & \\
\hline & Yes & 30.1 & $1.66[1.11-2.46)$ & & $1.71[1.11-2.64)$ & 0.015 \\
\hline Perineoplasty & No & 20.8 & 1 & 0.057 & ------ & \\
\hline & Yes & 28.6 & $1.52[0.98-2.35)$ & & ------ & ------ \\
\hline Diabetes & No & 21.3 & 1 & 0.136 & ------ & \\
\hline & Yes & 26.5 & $1.33[0.91-1.95)$ & & ------ & ----- \\
\hline Cardiovascular disease & Lowrisk & 18.8 & 1 & & & \\
\hline & Intermediaterisk & 25.4 & $1.47[1.05-2,06)$ & 0.078 & ------ & \\
\hline & High risk & 24.2 & $1.38[0.74-2,57)$ & & ------ & ------ \\
\hline Depression & Minimalormild & 20.8 & 1 & 0,003 & ------ & \\
\hline & Moderateorsevere & 33.1 & $1.88[1.24-2.86)$ & & ------ & ------ \\
\hline Metabolicsyndrome & No & 20.2 & 1 & 0.157 & ------ & ------ \\
\hline & Yes & 24.2 & $1.26[0.91-1.75)$ & & ------ & \\
\hline
\end{tabular}

\section{DISCUSSION}

Through a self-report done by a validated questionnaire, the prevalence of urinary incontinence and associated risk factors in climacteric women assisted in Family Health Strategy were evaluated. The study done with $^{[16]}$,perimenopausal women found similar results to this study. The data confirms that in the analyzed sample, even considering that the prevalence of urinary incontinence tends to increase in the climacteric period because of the reduction of protective factors ${ }^{[3]}$, the present study showed that women which were followed up on by the Family Health Strategy, even with a profile of lower education, older women, white race and are considered the main non-behavioral risk factors for urinary incontinence ${ }^{[5]}$, these have a lower prevalence of urinary incontinence compared to other studies conducted in Brazil in premenopausal women, as Reigota et al. ${ }^{[11]}$ which found a prevalence of $52.3 \%$, and Sacomori et al. ${ }^{[17]}$ which found a prevalence of urinary incontinence of $30.7 \%$. Considering the different age groups covered in the study, despite having found no association of age with urinary incontinence in the adjusted analysis, $25.8 \%$ of the women with urinary incontinence, were over 52 years of age. This result matches with other studies that show aging as one of the main factors associated with urinary disorders ${ }^{[5,18]}$. 
Getting old can cause changes in muscle contraction force detrusor which also may present incomplete bladder emptying and may also impair coordination between the sympathetic and parasympathetic systems which can cause involuntary contractions of the muscle ${ }^{[19]}$. Although education has not shown any association with urinary incontinence in the adjusted analysis, agreeing with the discoveries of $[4,5,17]$, low education is related to less access to information, preventive and therapeutic measures ${ }^{[5]}$, and many women consider the urinary incontinence due to the natural aging process. In this context, we see the need for health education activities in the community to address the issue, as well as public policy support and disease prevention. Regarding skin color, despite having had no association in the adjusted analysis, the crude analysis showed itself significant and consistentwith what was found in literature. That white women, due to differences in anatomy, urethraled resistance and structural support of the pelvic floor, have a higher risk of urinary incontinence when compared to black women ${ }^{[20]}$. The sedentary lifestyle variables and irregular physical activity were associated with urinary incontinence. Considering that the lack of practicing physical activities assume obvious proportions from women that are 40 years of age ${ }^{[21]}$, and combined with this factor, according to the results of this study, obesity and overweight can be identified as a risk factors for gettingurinary incontinence ${ }^{[9-11,22]}$, having seen that, increased Body Mass Index can cause chronic increased intra-abdominal pressure and weaken the structures of the pelvic support ${ }^{[23]}$. The increased pressure may hinder the mechanisms of urethral continence, by reducing the urethral pressure gradient, precipitating or exacerbating the urinary incontinence ${ }^{[24]}$. Another variable observed was in relation to smoking. Cigarette smoking may cause adverse effects on blood vessels, estrogen levels and collagen synthesis, making it easy for the occurrence of urinary incontinence ${ }^{[23]}$.Akkus and Pinar ${ }^{[8]}$ have shown that smoking is one of the modifiable risk factors for urinary incontinence. The greater the number of cigarettes smoked the greater the severity in urinary incontinence ${ }^{[25]}$.

Regarding clinical and obstetric factors, which may be determinant variables forurinary incontinenceoccurrences ${ }^{[26]}$, the pathology study showed that menopausal symptoms, ovarian cyst and episiotomy are associated with the disease. The greater the perception of women in relation to climacteric symptoms ${ }^{[27]}$, the greater the negative impact on quality of life ${ }^{[11]}$. Another factor that draws attention is regarding episiotomy. Due to the worsening of the perineal trauma caused by episiotomy during vaginal birth, this was associated with the urinary incontinence, which corroborates the study of Akkus and Pinar ${ }^{[8]}$. The relationship between ovarian cysts and urinary incontinence is still limited and inconclusive in the scientific literature. It is believed that most ovarian cysts can compress the volume of the bladder leading to an involuntary leak of urine, it is suggested that ovarian cysts can compress the bladder is related to its size, however, more research is needed. Another possibility is that these women develop overweight/obese due to ovarian pathology and, consequently, increase intra-abdominal pressure, favoring urinary incontinence. Some limitations of this study can be considered. The information was self-reported without aclinical diagnosis being made which makes it difficult to measure severity of the disease. It is worth mentioning the need for further studies with cohort actionsand longitudinal approaches to verify the connections between cause and effect and between the variables identified as predisposing to the occurrence of urinary incontinence, since the cross-sectional study measures the exposure and outcome but not proving its temporality. On the other hand, the sample was representative and the conclusions can be extrapolated to climacteric women assisted in primary health care, which increases the relevance of the work. In this context, the discoveries have important implications for public health policies aimed at preventing urinary incontinence in premenopausal women, in order to seek early diagnosis and treatment mitigating its consequences on health and quality of life for women. It also proposes greater vigilance to injuries in the climacteric, by creating information systems for effective health, providing information and health indicators in primary care and enabling knowledge, monitoring and systematization of data on the menopause in health care networks. In addition, taking up a healthy lifestyle is necessary for preventing diseases, since modifiable factors such as obesity, smoking and sedentary lifestyles were significantly correlated tourinary incontinence.

\section{CONCLUSIONS}

It is possible to conclude that the presence of modifiable factors such as being sedentary, smoking, overweight, present severe symptoms of menopause, having done episiotomy and the presence of ovarian cysts were associated with the urinary incontinence. Research that addresses the issue in population groups at highest risk is fundamental to improve knowledge of the disease, considered one of the greatest geriatric syndromes, chronic and benign.

\section{REFERENCES}

Abrams P, Cardozo L, Fall M, Griffiths D, Rosier P, Ulmsten U, et al. The standardization of terminology in lower urinary tract function: report from the standardization sub-committee of the International Continence Society. Urology.2003; 61:37-49.

Aguilar-Navarro S, NavarreteReyes-AP, Grados-Chavarria BH, Garcia-Lara JM, Amieva H, Avila-Funes JA. The severity of urinary incontinence decreases health-related quality of life Amongcommunity-dwelling elderly. JGerontol A BiolSci Med Sci. 2012; 67: 1266-71.

Akkus Y, Pinar G. Evaluation of the prevalence, type, severity, and risk factors of urinary incontinence and its impact on quality of life Among women in Turkey. IntUrogynecol. 2015; 5.

Brazilian Institute of Geography and Statistics [IBGE). Summary of Social Indicators: an analysis of the living conditions of the population. Studies and Research.2013; 32.

Brito LG, Brito LM, Chein MB, Malheiros ES, Duarte TB, PintoNeto AM. Stress urinary incontinence in climacteric women in the northeastern Brazilian municipality: the household survey. IntUrogynecol J. 2012; 23: 639-45.

Comission E. Special Eurobarometer-Sport and Physical Activity. European Comission: Brussels. 2010.

Hannestad YS, Rortveit G, Daltveit AK, Hunskaar S. Are smoking and other lifestyle factors associated with female urinary incontinence? The Norwegian EPINCONT Study.BJOG.2003; 110: $247-54$

HJ Jones, AJ Huang, Subak LL, Brown JS, Lee KA. Bladder Symptoms in the Early Menopausal Transition.J Womens health[Larchmt).2016; 25: 457-63.

Hsu A, Conell-Price J, Stijacic Cenzer I, Eng C, Huang AJ, RiceTrumble $\mathrm{K}$, et al. Predictors of urinary incontinence in community-dwelling frail older adults with diabetes mellitus in a cross-sectional study. BMC Geriatr.2014; 14: 137.

Kirss F, Lang K, K Toompere, Veerus P. Prevalence and risk factors of urinary incontinence Among Estonian postmenopausal women. SpringerPlus.2013; 2:524.

Leroy LS, Lopes MHBM, Shimo AKK. Urinary incontinence in women and racial aspects: a literature review. Text Enferm context.2012; 21: 692-701.

Liu B, Wang L, Huang SS, Wu Q, Wu DL. Prevalence and risk factors of urinary incontinence Among Chinese women in Shanghai.Int J ClinExp Med. 2014; 7: 686-96.

Marques LP, Schneider IJC, Giehl MWC Before DL, d'Orsi E. Demographic, health conditions, and lifestyle factors associated with urinary incontinence in elderly from Florianópolis, Santa Catarina, Brazil. Rev Bras Epidemiol. 2015; 18: 595-606.

Molarius A, Seidell JC, Sans S, Tuomilehto J, Kuulasmaa K. Varying sensitivity of waist action levels to identify subjects with overweight or obesity in 19 Populations of the WHO MONICA Project. J ClinEpidemiol. 1999; 52: 1213-24.

Moreno-Vecino B, Arija-Blazquez A, Pedrero-Chamizo R, Alcazar J, Gomez-Cabello A, Perez-Lopez FR, et al. Associations between obesity, physical fitness, and urinary incontinence in non- 
institutionalized postmenopausal women: The elderly EXERNET multi-center study. Maturitas.2015; 82: 208-14.

Obesity: Preventing and managing the global epidemic. Report of a WHO consultation.World Health Organ Tech Rep Ser. 2000; 894: 1-253.

Pedro AO, Pinto-Neto AM, Costa Paiva LHS, Osis MJD, Hardy EE. Climacteric syndrome: a population-based study in Brazil. Cad SaudePublica.2003; 37.

Reigota RB, Pedro AO, de Souza Santos Machado V, Costa Paiva L, Pinto-Neto AM. Prevalence of urinary incontinence and its association with multimorbidity in women aged 50 years or older: A population-based study. NeurourolUrodyn. 2016; 35: $62-8$.

Sacomori CNNB, Cardoso FL. Urinary incontinence in women seeking preventive screening for cervical cancer: sociodemographic and behavioral factors. Cad Saúde Pública.2013; 29: 1251-9.

Schneider JSNAS. Brazilian Demographic Transition and the Strategic Role of Youth.Espace Populations sociétés.2015; 2.

Sensoy N, N Dogan, Ozek B Karaaslan L. Urinary incontinence in women: prevalence rates, risk factors and impact on the quality of life. J Med Sci. 2013; 29: 818-22.
Solano JPC, Scazufca M, Menezes PR. Frequency of symptoms in the last year of life of low-income elderly in São Paulo: crosssectional study with informal caregivers. RevBrasEpidemiol 2011; 14: 75-85.

Tamanini JT, Dambros M, D'Ancona CA, PC Palma Rodrigues Netto $\mathrm{N}$, Jr. Validation of the "International Consultation on Incontinence Questionnaire - Short Form" [ICIQ-SF) is Portuguese. RevSaude Publica. 2004; 38: 438-44.

Tamanini JT, Lebrão ML Duarte YA, JL Santos, Laurenti R. Analysis of the prevalence of and factors associated with urinary incontinence among elderly people in the municipality of Sao Paulo, Brazil: SABE study [Health, Wellbeing and Aging). Cad SaudePublica.2009; 25: 1756-62.

Tang DH, Colayco DC, Khalaf KM, Piercy J, Patel V, Globe D, et al. Impact of urinary incontinence on healthcare resource utilization, health-related quality of life and productivity in Patients with overactive bladder. BJU Inter. 2014; 113: 484-91.

Townsend MK, Curhan GC, Resnick NM, Grodstein F. BMI, waist circumference, and incident urinary incontinence in older women. Obesity [Silver Spring).2008; 16: 881-6.

Weinberg AE, Leppert JT Elliott CS. Biochemical Measures of Diabetes are Not Independent Predictors of Urinary Incontinence in Women. J Urology. 2015; 194: 1668-74. 